UDC 342.41

LBC 67.400

\title{
JUSTICE AS A PRINCIPLE OF LAW AND CORNERSTONE OF FORMING LAWFUL BEHAVIOR
}

\author{
Sofya R. Deryugina \\ Volgograd Institute for the Humanities, Volgograd, Russian Federation
}

\begin{abstract}
Introduction: the problem of justice and its relationship with the law has been an actual problem since the ancient times. One of the purposes of the legal regulation is a compromise between the subjective justice and objective law (the law respectively, which embodies the right) for the consolidation of the social groups and the society as a whole. However, justice is always subjective. The law can never fully express and realize the absolute justice, because there are no ideas of justice which are common to all citizens. The objective of the study is to analyze the correlation of the categories of justice and legitimacy and their impact on the legal education of children and youth. The scientific methods used are the following (logical, systematic and functional) and private law methods (formal and legal, comparative legal ones). Results: there has been considered the concept of justice, the problem of its impact on the law as a whole, and on the legal education of children and youth. There has been raised the problem of correlation of the subjective and objective justice and the possibility of reflecting this principle in law. There has been proved the mutual influence of law and justice. There have been indicated the obstacles to the creation of no discriminating laws for the whole society. There have been made the conclusions on the impact of understanding the justice of the laws on the process of the legal education of children and youth. There have been determined the reasons that prevent the creation of an ideal model of law based on justice. There has been reasoned that law can only express common justice (and then, ideally), i.e., the justice of the society as a whole, or the justice for the certain social groups.
\end{abstract}

Keywords: justice, legitimacy, legal education, law, right, subjective and objective aspects in law.

УДК 342.41

ББК 67.400

\section{СПРАВЕДЛИВОСТЬ КАК ПРИНЦИП ПРАВА И ОСНОВА ФОРМИРОВАНИЯ ПРАВОМЕРНОГО ПОВЕДЕНИЯ}

\author{
Софья Романовна Дерюгина \\ Волгоградский гуманитарный институт, г. Волгоград, Российская Федерация
}

Введение: проблема справедливости и ее соотношения с правом является актуальной с древнейших времен. Одна из целей правового регулирования - это достижение компромисса между субъективной справедливостью и объективным правом (соответственно и законом, в котором право получает свое воплощение) для консолидации социальных групп и всего общества в целом. Однако справедливость всегда субъективна. Право никогда не сможет полностью выразить и реализовать абсолютную справедливость, потому что отсутствуют общие для всех граждан представления о справедливости. Цель исследования: проанализировать соотношение категорий справедливости и законности и их влияние на правовое воспитание детей и м молодежи. Методы: при проведении исследования использовались общенаучные методы (логический, системный, функциональный) и частноправовые методы (формально-юридический, сравнительно-правовой).

Результаты: рассмотрено понятие справедливости, проблемы ее влияния на право в целом и на правовое воспитание детей и молодежи. Подняты проблемы соотношения субъективной и объективной справедливо靕 сти и возможности отражения данного принципа в нормах права. Обосновано взаимное воздействие права и справедливости. Указано на причины, препятствующие созданию справедливых законов для всего общества в целом. Обоснованы выводы о воздействии понимания справедливости законов на процесс правового воспитания детей и молодежи. Установлены причины, препятствующие созданию идеальной модели права, 


\section{ТЕОРИЯ И ПРАКТИКА ГОСУДАРСТВЕННО-ПРАВОВОГО РАЗВИТИЯ}

основанного на справедливости. Аргументировано, что в законе может выражаться лишь общая справедливость (и то в идеале), то есть справедливость общества в целом, либо справедливость для отдельных социальных групп.

Ключевые слова: справедливость, законность, правовое воспитание, закон, право, субъективное и объективное в праве.

\section{Введение}

Понятие «справедливость» вездесуще пронизывает все области жизнедеятельности общества. Исконно юридическая наука основывается на справедливости. Нормы морали приобретали государственный характер посредством закрепления их в нормативных актах.

Изначально любой человек, будь то ребенок, представитель молодежи или старшего поколения, оценивает поведение другого человека или какие-то события с точки зрения справедливости или несправедливости.

И если ребенок считает поведение или событие справедливым, ему легче воспринимать его, следовать ему, оценивать результаты. Поэтому изначально основная идея права заключалась в том, чтобы закрепить наиболее справедливые законы, исполнение которых будет соответствовать и мировоззрению граждан, и их пониманию справедливости.

Как социальные регуляторы, право и справедливость всегда обращены к свободе человека и его ответственности за свои действия. Право и справедливость употребляются как тесно взаимосвязанные понятия: когда ссылаются на норму права, то ожидают, что значимость этой нормы признает всякий человек, поскольку эта норма справедлива.

«Осуществление права по своей природе не может обходиться без запретов, поскольку с их помощью достигается конкретизация пределов того, что именно позволено обладателю субъективного права» [4, с. 95]. Но все запреты должны быть сформулированы с учетом принципа справедливости.

Справедливость выражает соответствие между индивидом и его социальным положением, между правами и обязанностями, между деяниями и воздаяниями, преступлением и наказанием. Несоответствие в этих отношениях расценивается как несправедливость. Несправедливость ослабляет и разрушает любое общество.
Для правильного понимания данного вопроса, имеющего изначально философскую направленность, необходимо разобраться, что подразумевает под собой «справедливость».

\section{Влияние категории справедливости на формирование правомерного осуществления гражданских прав}

В юридической науке нет однозначного и единого определения понятия справедливости. Ю.И. Бытко отмечает, что «справедливость как правовая и этическая категория это субъективное представление о пределах дозволенного для себя по отношению к другим и других по отношению к тебе, а право не что иное, как писаное правило об этих пределах» [2, с. 168].

По мнению М.Н. Руткевича, «в понятии справедливости фиксируется моральное и правовое представление о том, что соответствует и что не соответствует законам, нормам права и общественной, господствующей в обществе морали» [8, с. 61].

Ж. Ламетри считал, что «справедливым может быть признано только то, что соответствует интересам общества» [1, с. 611].

В соответствии с Толковым словарем русского языка Д.Н. Ушакова справедливость - это «беспристрастное соблюдение истины» [11, с. 124]. Немного иначе определяет данную категорию С.И. Ожегов, раскрывая его наиболее полно посредством слияния с другим однокоренным словом: справедливый - «действующий беспристрастно; соответствующий истине; осуществляемый на законных и честных основаниях; истинный, правильный» [7, с. 1992].

Основываясь на проанализированных научных определениях справедливости, можно заключить, что сущность данного понятия составляет наличие истины, которая подсознательно ассоциируется с законностью, а следовательно, и с правом. Также необходимо 
C.P. Дерюгина. Справедливость как принцип права и основа формирования правомерного поведения

подчеркнуть, что среди многочисленных синонимов справедливости, таких как достоверность, непредвзятость, объективность, правильность, честность, встречается так же и такое синонимичное, а значит, схожее по смыслу понятие - законность. Далее, в соответствии с логической цепочкой соотношения связи данных понятий необходимо дать определение законности: «Законность - это неукоснительное исполнение законов и соответствующих им правовых актов всеми органами государства, должностными и иными лицами» $[10$, c. 24]. Необходимо заметить непреодолимое сходство синонимов справедливости и законности, из чего следует сделать вывод о равнозначности данных понятий. А значит, тезис «по закону - значит, по справедливости» является достоверным и фактически обоснованным с теоретической стороны. При таком подходе можно получить идеальную конструкцию, при которой право, а следовательно, и закон, в котором оно выражается, всегда справедливы. Однако это утопия.

Проблема справедливости, ее взаимоотношения и соотношения с правом является актуальным вопросом во все времена. Относительно теоретического единства права и справедливости указано выше, однако с практической стороны данной проблемы нельзя объективно заявлять о такой же синонимичности. Более того, нельзя исключать сложившееся противопоставление данных понятий. Об этом свидетельствует общее отношение социума к правосудию, а также к представителям в основном исполнительной власти.

Разность справедливости и закона является не новшеством для русского общества, а наоборот, хорошо сложившейся традицией. В России первый свод законов Русская Правда принят в 1280 году. С одной стороны, «Русская Правда обеспечила единообразный подход к правовому регулированию качественно однородных общественных отношений, объединивших правовое поле разрозненных территорий российского государства, и положила начало созданию кодифицированного законодательства Древней Руси» [6, с. 16]. С другой - она закрепляла социальное неравенство и потому могла трактоваться как несправедливый закон. От того и укоренилось в русском сознании, что закон несправедлив, что нашло свое отражение в поговорке: «где суд, там и неправда» [9].

Справедливость присуща каждому человеку, и поэтому она у каждого своя. Нельзя говорить об общей, глобальной и равной для всех справедливости в отличие от права.

Право, а соответственно, и законодательство, его отражающее, обеспечивается мерами государственного принуждения. Закон не может быть всесилен без силы государства. Если признать, что закон - это справедливость, то закономерно будет и следующее утверждение: справедливость не может быть всесильна без силы государства или справедливость обеспечивается мерами государственного принуждения. Таким образом, справедливость и государственное принуждение ставятся в данной логической цепочке в один ряд.

Необходимо подчеркнуть возникший казус между законом и справедливостью, а именно основой закона является справедливость, достигать которой следует с использованием мер государственного принуждения, которые априори не могут являться средством достижения справедливости.

Все сказанное позволяет сформулировать общую формулу соотношения закона и справедливости: «без принуждения справедливость бессильна, а закон без справедливости - бесчеловечен» [3, с. 243].

\section{Выводы}

Из всего вышесказанного следует, что в законе может выражаться лишь общая справедливость (и то в идеале), то есть справедливость общества в целом либо справедливость для отдельных социальных групп (инвалидов, пенсионеров, молодежи и проч.). Являясь результатом борьбы различных общественных сил, право, а с ним и закон не могут быть одинаково справедливыми для каждой из этих общественных сил, в праве всегда будет оставаться момент предпочтения интересов одних, более властных или больших социальных групп интересам других, менее властных или меньших по количеству групп.

Справедливый закон должен обеспечивать права и свободы человека, учитывать различные интересы и способствовать достижению консенсуса в обществе. Справедли- 


\section{ТЕОРИЯ И ПРАКТИКА ГОСУДАРСТВЕННО-ПРАВОВОГО РАЗВИТИЯ}

вость, оказывая влияние на право, сама нуждается в опоре на соответствующие правовые нормы. В праве требования справедливости приобретают четко сформулированный, фиксированный характер. Именно право становится основным нормативным средством реализации принципа справедливости [5, с. 29].

Поэтому целью демократического государства является достижение компромисса между субъективной справедливостью и объективным правом (соответственно и законом, в котором право получает свое воплощение) для консолидации социальных групп и всего общества в целом.

В заключение следует сказать, что справедливость является абстрактным и субъективным понятием. Нет сформулированного и обоснованного определения данной категории в праве, поскольку нет однозначного мнения на этот счет. Право никогда не сможет полностью выразить и реализовать абсолютную справедливость, потому что отсутствуют общие для всех граждан представления о справедливости. Единого выражения значения справедливости нельзя достичь, так как само понятие является субъективной и постоянно изменяющейся категорией.

Следовательно, объективной справедливости как таковой нет. Закон предназначен для обеспечения сохранности интересов всего общества. Право в своем юридическом воплощении тем и отличается от справедливости - оно едино и независимо от субъективных мнений индивидов. Закон един, и каждый обязан его соблюдать.

\section{СПИСОК ЛИТЕРАТУРЫ}

1. Антология мудрости / сост. В. Шойхер. М. : Вече, 2007. - 848 c.

2. Бытко, Ю. И. Справедливость и право / Ю. И. Бытко. - Саратов : Изд-во Сарат. гос. акад. права, 2005. - $71 \mathrm{c.}$

3. Галушко, В. Г. Принцип справедливости в социальном взаимодействии / В. Г. Галушко. - СПб. : СПбГИПСР, 2014.

4. Дерюгина, Т. В. Пределы осуществления прав собственника на жилое помещение: коллизионные аспекты правового регулирования / Т. В. Дерюгина // Вестник Волгоградского государственного университета. Серия 5, Юриспруденция. - 2015. № $3(28)$. - C. 92-96.
5. Иванова, С. А. Некоторые проблемы реализации принципа социальной справедливости, разумности и добросовестности в обязательственном праве / С. А. Иванова // Законодательство и экономика. - 2005. - № 4. - С. 29-34.

6. Иншакова, А. О. Русская Правда как первоисточник унифицированного гражданско-правового развития Русского государства / А. О. Иншакова // Вестник Волгоградского государственного университета. Серия 5, Юриспруденция. - 2015. - № 4 (29). - C. 10-18.

7. Ожегов, С. И. Словарь русского языка / С. И. Ожегов. - 22-е изд. - М. : Рус. яз., 1990. $2123 \mathrm{c}$.

8. Руткевич, М. Н. Социалистическая справедливость / М. Н. Руткевич // Социологические исследования. - 1986. - № 3. - С. 61-75.

9. Столяров, А. М. Русский архетип: закон и справедливость / А. М. Столяров. - Электрон. текстовые дан. - Режим доступа: http://badnews.org.ru/ news/russkij_arkhetip_zakon_i_spravedlivost/201008-14-2603. - Загл. с экрана.

10. Сухарев, А. Я. Большой юридический словарь / А. Я. Сухарев, В. Е. Крутских. - М. : ИнфраM, 2003. $-356 \mathrm{c}$.

11. Ушаков, Д. Н. Толковый словарь русского языка / Д. Н. Ушаков. - М. : Сов. энцикл. : ОГИЗ : Гос. изд-во иностр. и нац. слов, 1935-1940. - Т. 4. $564 \mathrm{c}$.

\section{REFERENCES}

1. Shoykher V., ed. Antologiya mudrosti [Anthology of Wisdom]. Moscow, Veche Publ., 2007. $848 \mathrm{p}$.

2. Bytko Yu.I. Spravedlivost i pravo [Justice and Law]. Saratov, Izd-vo Sarat. gos. akad. prava, 2005. $71 \mathrm{p}$.

3. Galushko V.G. Printsip spravedlivosti v sotsialnom vzaimodeystvii [Principle of Fairness in Social Interaction]. Saint Petersburg, SPbGIPSR Publ., 2014.

4. Deryugina T.V. Predely osushchestvleniya prav sobstvennika na zhiloe pomeshchenie: kollizionnye aspekty pravovogo regulirovaniya [Limits of the Owner's Right to Accomodation Facilities: Conflicts at the Legal Regulation]. Vestnik Volgogradskogo gosudarstvennogo universiteta. Seriya 5, Yurisprudentsiya [Science Journal of Volgograd State University. Jurisprudence], 2015, no. 3 (28), pp. 92-96.

5. Ivanova S.A. Nekotorye problemy realizatsii printsipa sotsialnoy spravedlivosti, razumnosti I dobrosovestnosti v obyazatelstvennom prave [Some Problems of Implementation of the Principle of Social 
C.P. Дерюгина. Справедливость как принцип права и основа формирования правомерного поведения

Justice, Reasonableness and Good Faith in the Law of Obligations]. Zakonodatelstvo i ekonomika, 2005, no. 4, pp. 29-34.

6. Inshakova A.O. Russkaya Pravda kak pervoistochnik unifitsirovannogo grazhdanskopravovogo razvitiya Russkogo gosudarstva [Russkaya Pravda as the Source of the Unified Civil Law of the Russian State]. Vestnik Volgogradskogo gosudarstvennogo universiteta. Seriya 5, Yurisprudentsiya [Science Journal of Volgograd State University. Jurisprudence], 2015, no. 4 (29), pp. 10-18.

7. Ozhegov S.I. Slovar russkogo yazyka [Dictionary of Russian Langusge]. 22nd ed. Moscow, Russkiy yazyk Publ., 1990. 2123 p.
8. Rutkevich M.N. Sotsialisticheskaya spravedlivost [Socialist Justice]. Sotsiologicheskie issledovaniya, 1986, no. 3, pp. 61-75.

9. Stolyarov A.M. Russkiy arkhetip: zakon $i$ spravedlivost [Russian Archetype: Law and Justice]. Available at: http://badnews.org.ru/news/russkij_ arkhetip_zakon_i_spravedlivost/2010-08-14-2603.

10. Sukharev A.Ya., Krutskikh V.Ye. Bolshoy yuridicheskiy slovar [Big Dictionary of Law]. Moscow, Infra-M Publ., 2003. 356 p.

11. Ushakov D.N. Tolkovyy slovar russkogo yazyka [Explanatory Dictionary of Russian Language]. Moscow, Sov. entsik1.; OGIZ; Gos. izd-vo inostr. i nats. slov, 1935-1940, vol. 4. 564 p.

\section{Information About the Author}

Sofya R. Deryugina, 3rd Year Student, the Law Department, Volgograd Institute for the Humanities, Gribanova St., 12, 400011 Volgograd, Russian Federation, sofiaderugina3764@mail.ru.

\section{Информация об авторе}

Софья Романовна Дерюгина, студентка 3 курса юридического факультета, Волгоградский гуманитарный институт, ул. Грибанова, 12, 400011 г. Волгоград, Российская Федерация, sofiaderugina3764@mail.ru. 